\section{Koncertlivets hukommelse}

\author{
Et blik på koncertprogrammer som \\ kildemateriale - $\mathrm{i}$ hundredåret for \\ Småtrykssamlingens oprettelse
}

\section{Afseniorforsker Claus Rollum-Larsen}

$\mathrm{E}$ $\mathrm{n}$ af de væenentligste kilder til beskrivelse af musiklivet - dets art og omfang - er trykte koncertprogrammer. Med det offentlige koncertlivs opståen i 1800-tallet kom der et behov for sådanne programmer, for dels øgedes antallet af koncerter i forhold til de mere private koncerter i de musikalske selskaber og foreninger i slutningen af 1700-tallet, dels, og nok så vigtigt, henvendte koncerterne sig nu til en stadig bredere skare af lyttere, for hvem de opførte komponister og værker ikke kunne forventes kendte. Herudover blev de trykte programmer en form for signaler til omverdenen om de betydelige koncertforetagender, der så dagens lys fra 1830erne, og de blev en slags souvenirs fra de store koncertoplevelser. Programmerne fra Musikforeningen, der blev grundlagt i 1836, bærer præg af disse funktioner, men endnu tydeligere ses det på dem der benytredes i Caciliaforeningen (stiftet 1851) fra slutningen af 1800-tallet; denne forenings ambitiøse repertoirepolitik afspejles i de elegante programblade på udsøgt blødt papir i relativt stort format. At Det Kongelige Bibliotek er i besiddelse af komplette samlinger af disse store foreningers koncertprogrammer er ikke mærkeligt. Foruden de er blevet indlemmet $\mathrm{i}$ biblioteket som følge af pligtafleveringsloven af 1697, har biblioteket overtaget begges arkiver. Ydermere synes foreningernes programmer at være blevet bevaret i ret stort omfang, muligvis fordi det har været nærliggende for foreningernes medlemmer at gemme programmerne, som udgjorde en helhed og dermed en dokumentation for den enkelte forenings virksomhed. Men det billede, der tegner sig af koncertlivet, er selvfølgelig langt mere omfattende og differentieret; til de mange enkeltstående koncerter i byens koncertsale eller kirker har der naturligvis også været trykte programmer, men i modsætning til hvad der gælder for foreningskoncerterne, kan man ikke umiddelbart afgøre, hvor meget der her, trods pligtafleveringsloven, mangler i Det Kongelige Biblioteks Småtrykssamling.

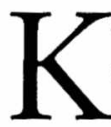
oncertprogrammerne, der næsten altid er daterede eller lader sig datere, opviser en stor spredning, hvad angår informationsmængde og kvaliteten af de enkelte oplysninger. Der er således langt fra de programmer, der blot benytter genrebetegnelser som "Arie" eller "Symphonie" uden præcisering af musikværkets nummer i en rækkefølge, toneart, opusnummer osv., til eksempelvis de programmer, der findes fra nogle af organisten Finn Reiffs koncerter i 1960erne, hvor ethvert værk er kortfattet, men entydigt beskrevet, og hvor de valgte orgelregistreringer til hver enkelt komposition er angivet; illustration nr.1 viser et af disse programmer, hvor registreringerne er indført $i$ et koordinatsystem. I dette tilfælde er der tale om en slags opførelsesrapport, som i sjælden grad dokumenterer den spillendes intentioner. Tilløb til en sådan form for dokumentation finder man allerede omkring år 1900, da dirigenten Joachim Andersen i 


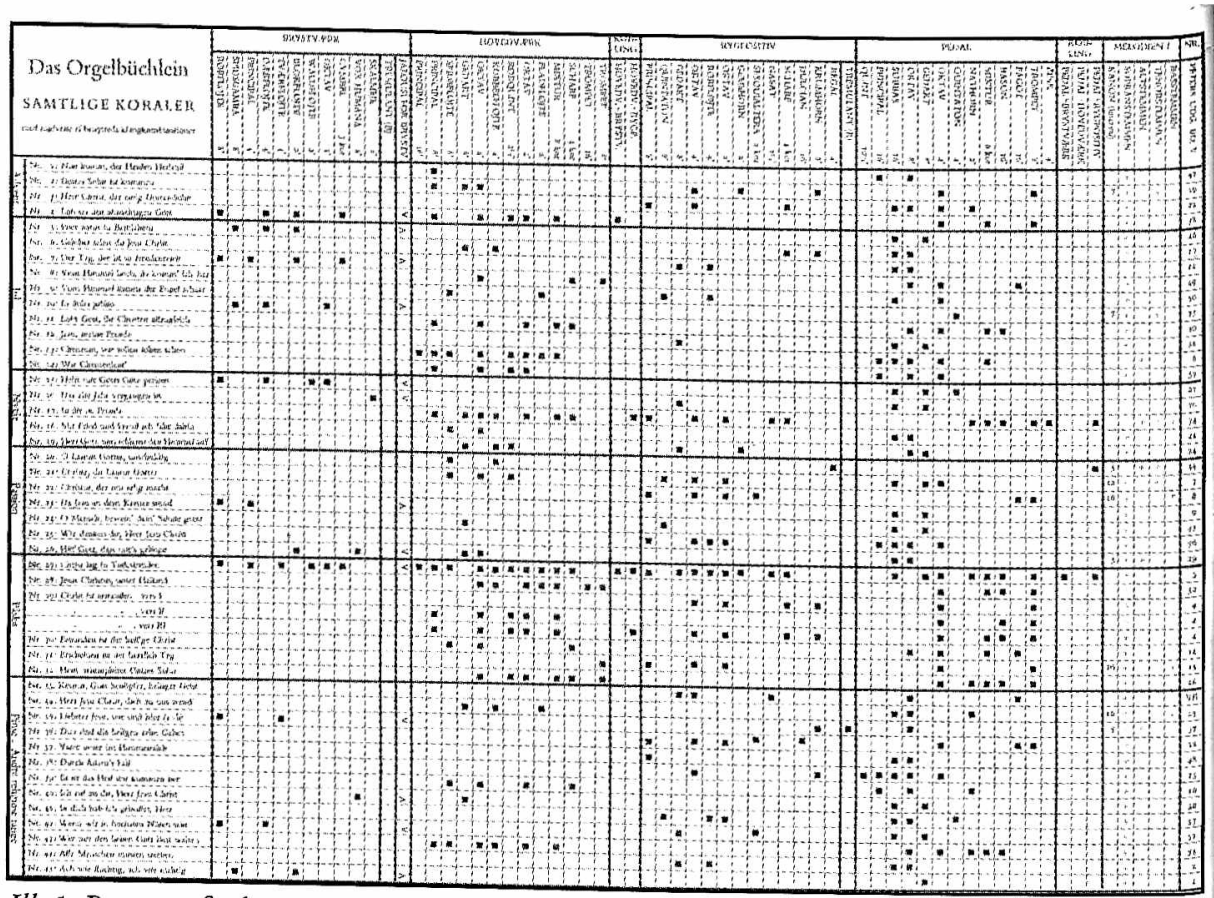

Ill. 1. Program fra koncert med organisten Finn Reiffi Trinitatis Kirke den 27. januar 1960.(Foto: Det Kongelige Bibliotek).

programmerne til nogle af sine PaleKoncerter angav orkesterbesætningen, og denne praksis blev senere taget op af Frederik Schnedler-Petersen i Københavns Filharmoniske Selskab, men først langt senere er sådanne besætningsoplysninger blevet gængse hos flere store orkestre.

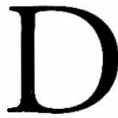
et siger sig selv, at den sidste type programmer, der rummer den udførlige dokumentation, er betydelig mere anvendelig til forskningsformål end den første, men selv om alle ønskelige oplysninger er til stede, bør man ikke forledes til at tro, at informationerne uden videre kan tages for gode varer. Tværtimod kan der let være foretaget ændringer i programmerne, uden at det fremgår af teksten. I nogle tilfælde er koncertprogrammet sendt til trykning i så god tid før koncerten, at det ikke har været muligt at indføre ændringer i teksten, og programmet er derefter blevet pligtafleveret. I andre tilfælde er der på selve koncertaftenen blevet ændret i programmet fx pga. sygdom. Denne sidste type ændringer er selvfølgelig heller ikke blevet indført i programmet, og man bliver umiddelbart kun opmærksom på dem, hvis der er indlagt et rettelsesblad (gerne på farvet papir), eller men det gælder naturligvis ikke de pligtafleverede programmer - hvis koncertgængeren har noteret i det. Det er selvfølgelig også forekommet, at koncerten er blevet aflyst, efter at programmet er blevet trykt og senere pligtafleveret af bogtrykkeren. 


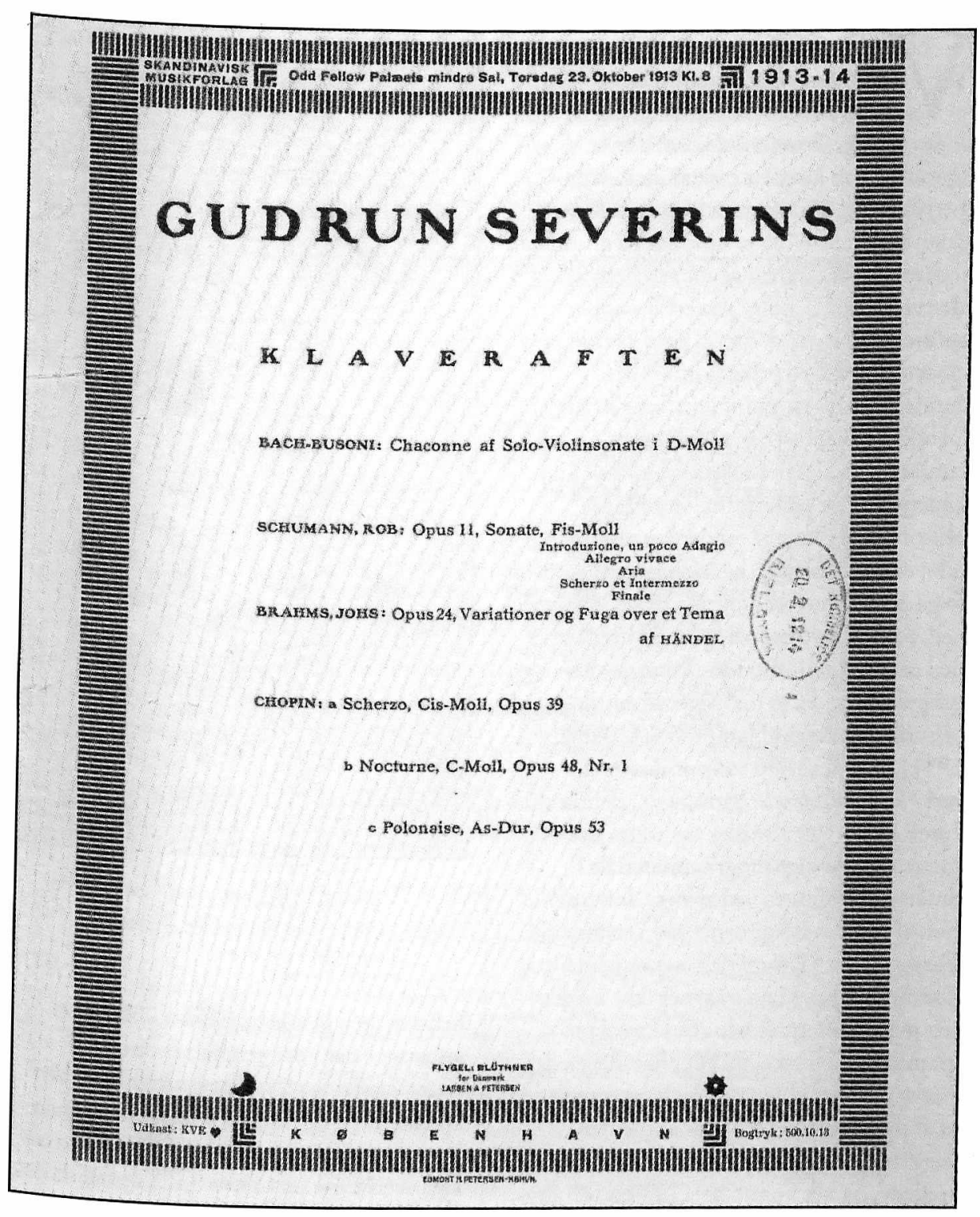

IIl. 2. Det er ikke almindeligt, at koncertprogrammer har sarlige astetiske kvaliteter; men der er dog undtagelser. Dette program fra en koncert med pianistinden Gudrun Severins den 23. oktober 1913 er således designet af den kendte arkitekt KnudV. Engelhardt (1882-1931). (Foto: Det Kongelige Bibliotek). 
$\mathrm{V}$

erifikation af koncertprogrammernes oplysninger er i bund og grund en uhyre vanskelig sag. Der findes tilfælde, hvor en avisanmeldelse af koncerten kan kaste lys over situationen, men ikke sjældent er anmeldelserne af en sådan karakter, at det er umuligt på grundlag af dem med sikkerhed at afgøre fx et værks identitet. Med henblik på verifikation af opførelser kan det derimod være nyttigt at ty til scrapbøger med programmer eller deciderede programsamlinger, som stammer fra udøvende kunstnere. I Småtrykssamlingen findes flere eksempler på denne kildetype, som kan rumme værdifulde tilskrifter. De fleste af bindene stammer fra udøvende kunstnere, og indholdet er som følge deraf centreret omkring disses virksomhed. Særlig interesse påkalder sig imidlertid den samling af indbundne koncertprogrammer, der er opbygget af musikhistorikeren Angul Hammerich (18481931), som fra 1880 var musikanmelder ved Nationaltidende. Samlingen, der dækker årene 1878-1901, skiller sig ud fra det meste af det øvrige programmateriale i Småtrykssamlingen ved at være dokumentation af én mands koncertbesøg i en årrække. Heldigvis var Hammerich en særdeles flittig koncertgænger, så man savner ikke meget, når man gennemser hans bind med programmer. Til forskel fra det pligtafleverede stof er de fleste af Hammerichs programmer så at sige redskaber fra hans anmelderværksted. Her kunne han orientere sig i det spillede, og her kunne han, om nødvendigt, notere små oplysninger. Således udgør denne programsamling for det første en dokumentation af Hammerichs anmelderarbejde, ${ }^{1}$ for det andet giver den med sit brede udsnit af programmer et særdeles godt indblik i Københavns koncertliv i perioden, ikke mindst fordi den er ordnet kronologisk uden

\section{Fisk Jubilee Singers.}

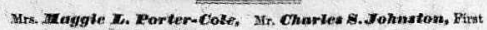
Sopraso and Mrtiteal Birectrees. Bass.

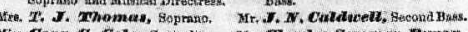

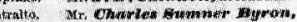

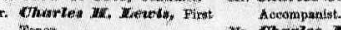

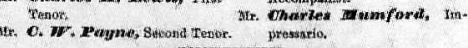

De thesto at Sangane pas fiask Jubttee Singera" Prograna ere Negersange tha dis atherikanshe Bydatater. Negerbefolkningen i disse stater yar Shaver, indil to ofter Borgerkrigen i 1806 bley befriade. Nogle at dette Selukabs arealemmer ers fedte blaver. Sungene, nom eré simple : dezes

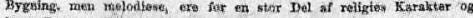

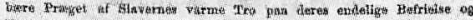

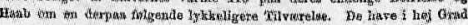

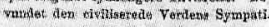

\section{Iste Koncert}

Tirsdag den 26 de Marts 1895 K1. 8 i Koncertpalzets store Sal. PROGRAM:

4

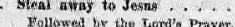

.......... Neyro Methd

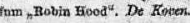

Bir. J. N. Calitwell.

. . . . . . Negro Meind

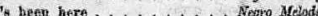

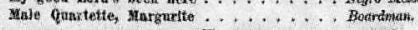

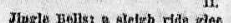

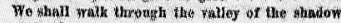

of death . . . . . . . . . . Negro Melud

Tesor solo, Mom

atr. 0 . W. Payne.

0 zest,

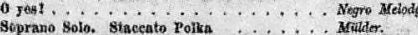

wire, M. L. F. cote.

Swing low, sweet Clurtat.

Pollowed is the Benedtetion

Flygel: Hornithig of Milier

Gy

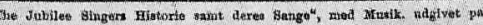

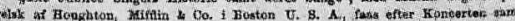

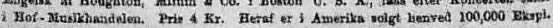

\section{Ill. 3. Program fra koncert med Fisk Jubilee} Singers. (Foto: Det Kongelige Bibliotek).

hensyntagen til koncertrækker, lokaliteter, kunstnere osv., der generelt benyttes til systematisering af Småtrykssamlingen. Ved at kaste et blik i Hammerichs bind făr man et vue over Københavns koncertliv, og man kan overbevise sig om, at omfanget af de musikalske tilbud var betragteligt.

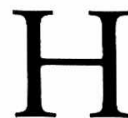

ammerich har ønsket at følge et bredt udsnit af tidens koncerter; man finder således programmer fra de betydelige symfonikoncerter med Det Kongelige Kapel og Johan Svendsen, de 
populære Pale-Koncerter med Joachim

Andersen, fra Koncertforeningen,

Caciliaforeningen, og selvfølgelig Musik-

foreningen, hvis formand Hammerich var i

en årrække. Desuden er kammermusik-

soiréerne med medlemmer af Det Kongelige
Kapel og de talrige solistkoncerter med hjemlige og rejsende kunstnere repræsenteret. Særlig opmærksomhed bør man vie programmet fra Fisk Jubilee Singers' koncert i Odd Fellow-Palæets store sal den 26. marts 1895. ${ }^{2}$ Dette program, (IIl. 3) der i øvrigt

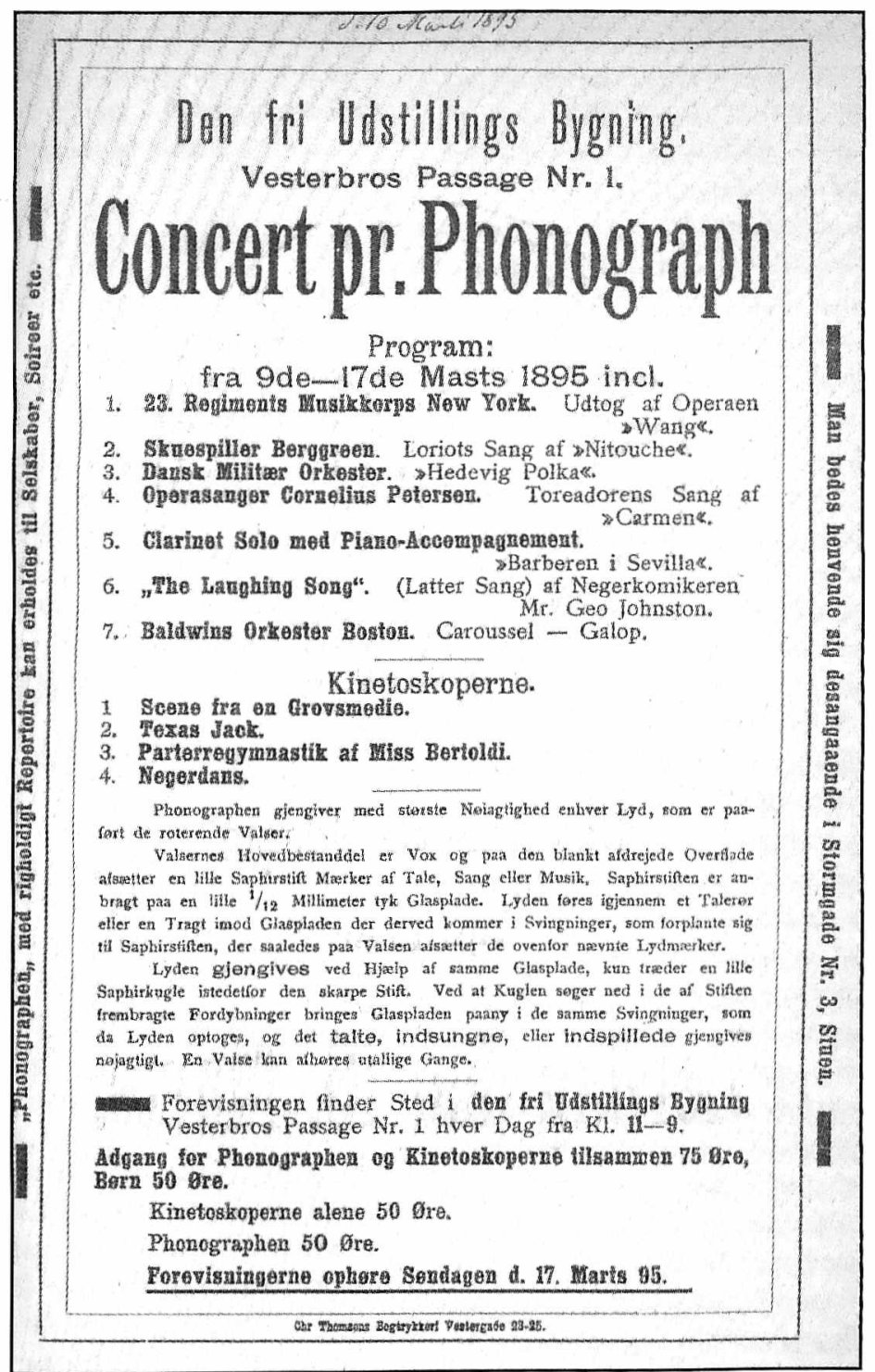

Ill. 4. Program fra koncert med fonograf den 10. marts 1895. (Det Kgl. Bibliotek). 
ikke findes andre steder i Småtrykssamlingen, vidner om et besøg af en gruppe farvede sangere, som fremførte negro spirituals m.m. Københavnerne hørte her eksempler på en musiktradition, som i det følgende århundrede skulle sætte sit præg på størstedelen af musikkulturen. Det er i øvrigt pudsigt, at der kort forinden, nemlig fra den 9. til 17. marts, blev afholdt noget så usædvanligt som en "Concert pr.

Phonograph" i Den fri Udstillings bygning på den daværende Vesterbros Passage (se Ill. 4). Her blev foredraget bl.a. "The Laughing Song" af "Negerkomikeren Geo Johnston og en "Negerdans". At vi overhovedet ved noget om denne begivenhed kan vi takke en anden "scrapbogsmager", kontorchef Jacob With, for.

$\mathrm{T}$ il spørgsmålet: Hvad kan Småtrykssamlingens koncertprogrammer bruges til i musikforskningsmæssig henseende, må man svare: Foruden til brede repertoireundersøgelser, $\mathrm{fx}$ centrerede om en enkelt koncertgivende forening, kan materialet belyse enkeltkunstneres koncertaktivitet. Til disse sidste hører udenlandske musikere på besøg i Danmark; det er således muligt at kortlægge Sergej Rachmaninovs, Fritz Kreislers, Edwin Fischers og mange andres koncerter i København og evt. provinsen. Gennem det måske mest omfattende materiale, Tivolis, kan man danne sig et detaljeret indtryk af dette gamle og omfattende etablissements store koncertvirksomhed. Arbejder man med vokalmusik, kan man være heldig i koncertprogrammer at finde den måske eneste kendte tekst evt. version af sådan til et musikværk. At Småtrykssamlingen desuden rummer materiale fra musikalske foreninger og selskaber (love, repertoirelister, medlemsfortegnelser, regnskaber etc.) samt tryksager fra engageringsbureauer, instrumenthandlere m.fl. betyder, at samlingen er uvurderlig til levering af oplysninger om musiklivet, samt at den som inspirationskilde må betegnes som noget nær uudtømmelig. Hvis samlingen også i fremtiden skal have værdi som kildemateriale og som sådan kunne dokumentere koncertlivet - være dets "hukommelse" - så skal pligtafleveringsloven fortsat efterleves. For forskningen er det fatalt, hvis et arkivs eller en samlings hukommelse svigter.

Noter:

${ }^{1}$ Hammerichs samling af egne dagbladsanmeldelser beror på Musikhistorisk Museum og Carl Claudius' Samling.

${ }^{2}$ Koncerten vil blive behandlet af Heinrich W. Schwab i artiklen "Spirituals im nördlichen Europa. Berichte, Bilder und Kommentare zu den Konzertreisen der Fisk Jubilee Singers im 19. Jahrhundert", Musik \& Forskning 27 (2002). 